\title{
Double Y-Stent Placement for Tracheobronchial Stenosis
}

\author{
Masahide Oki Hideo Saka Chiyoe Kitagawa Yoshihito Kogure Kouki Mori \\ Shigehisa Kajikawa Takashi Adachi \\ Department of Respiratory Medicine, Nagoya Medical Center, Nagoya, Japan
}

\section{Established Facts}

- The silicone Y-stent provides effective palliative treatment for patients with main carinal stenosis.

\section{Novel Insights}

- The silicone Y-stent can also be used for airway stenosis around the carina between the right upper lobe bronchus and the bronchus intermedius. Double Y-stent placement is technically feasible, safe and effective in certain cases.

\section{Key Words}

Airway obstruction · Airway stent $\cdot$ Bronchoscopy $\cdot$ Silicone stent $\cdot$ Y-stent

\begin{abstract}
The silicone stent has been widely used to re-establish airway patency for patients with airway stenosis. The ideal shape of the stent should be well adapted to the tracheobronchial anatomic structures, and its optimal length should cover the entire inner wall of the stenotic airway. Although the silicone $Y$-stent was developed as a dedicated prosthesis for main carinal stenosis, we often encounter patients with tracheobronchial stenosis that cannot be treated by a single silicone Y-stent. The present study reports 2 cases of malignant disease who underwent double Y-stent placement on
\end{abstract}

\section{KARGER}

Fax +41613061234 E-Mail karger@karger.ch www.karger.com (c) 2009 S. Karger AG, Basel 0025-7931/10/0793-0245\$26.00/0 www.karger.com/res the involved carina between the right upper lobe bronchus and the bronchus intermedius as well as on the involved main carina as a unit. The procedure provided successful palliation.

Copyright $\odot 2009$ S. Karger AG, Basel

\section{Introduction}

Silicone stent placement has become popular as a useful palliation for both malignant and benign airway stenosis $[1,2]$. Among many types and shapes of stents, the bifurcated silicone stent (the so-called Y-stent) provides effective palliative treatment for patients with main carinal stenosis [3, 4]. Additionally, this stent is also useful for patients with airway stenosis around the carina between 

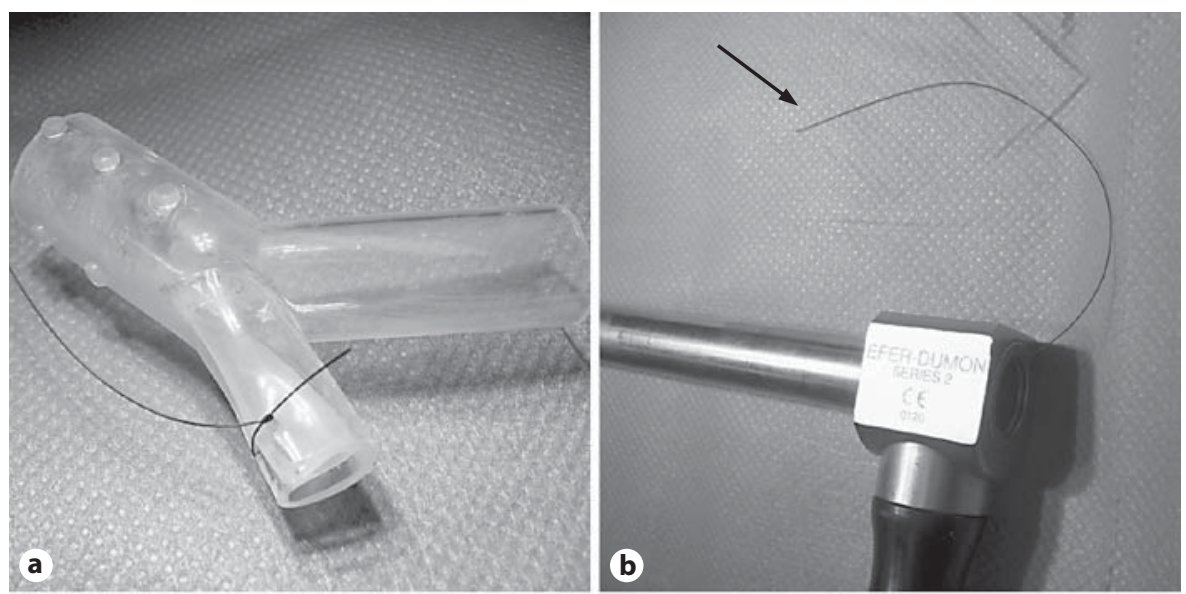

Fig. 1. a Folded limb of the Y-stent. b End of the nylon thread drawn through the stent introducer (black arrow). c Endoscopic flexible scissors (black arrow) for cutting the nylon thread (white arrow) inside the stent. The nylon thread (arrowheads) outside the stent is visible through the clear stent. d Combined Y-stents.
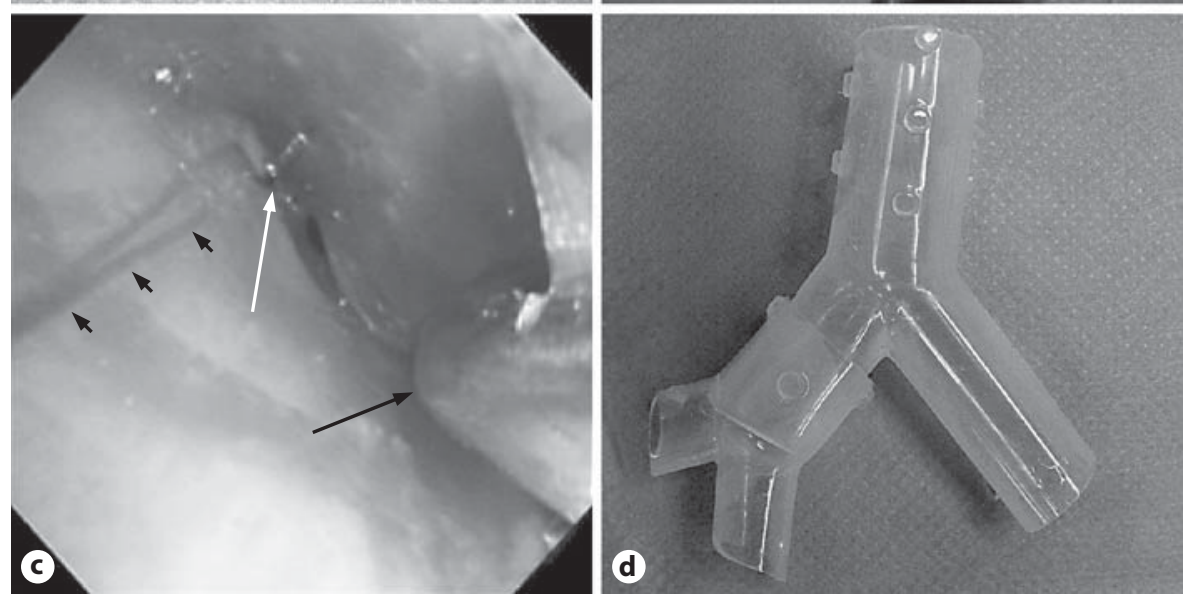

the right upper lobe bronchus and the bronchus intermedius (right carina 1, RC 1; nomenclature proposed by Prakash and Fontana) $[5,6]$. The Y-stenting technique on $\mathrm{RC} 1$ enabled us to maintain the patency of the right upper lobe bronchus.

We sometimes encounter patients with malignant involvement around both the main carina and RC 1 that requires stent placement. We report 2 cases of malignant disease with Y-stents placed on both the involved main carina and $\mathrm{RC} 1$ as a unit. The combined stent was a good fit, thus providing successful palliation.

\section{Technique}

All the procedures were performed under general anesthesia using a rigid and flexible bronchoscope. Before placing the stents, the airway lumen should be re-established by a bronchoscopic procedure combining argon plasma coagulation, electrocautery, balloon dilatation or rigid bronchoscopic debulking [7]. After that, the length and diameter of the stenosis are assessed using a flexible and rigid bronchoscope, an endobronchial ultrasonic probe with a balloon, as well as preprocedural static images as previously described [6].

First Stent Placement on RC 1

The optimal-sized Y-stent is selected and cut to the appropriate length. The peripheral orifices of the Y-stent to be placed on $\mathrm{RC} 1$ should be cut at an angle to assure a smooth flow and to avoid facing the bronchial wall. The Y-stent is placed on RC 1 using either of the 2 following techniques. (1) Pushing method: using a stent introducer system (EFER, La Ciotat, France), the Y-stent is inserted into the right main stem bronchus just above RC 1 . The stent is then grasped with a rigid forceps and pushed so that it straddles the bifurcation. (2) Pulling method: before stent insertion, the limb of the Y-stent for the right upper lobe bronchus is cut shorter than the limb for the bronchus intermedius. The rigid bronchoscope is advanced toward the bronchus intermedius as far as possible. Once both limbs of the Y-stent have been inserted into the bronchus intermedius, the stent is grasped with the rigid forceps and slowly withdrawn until a limb slips into the right upper lobe bronchus. Finally, the stent is pushed to fit on the bifurcation.

\section{Second Stent Placement on the Main Carina}

An additional Y-stent is then placed on the main carina. A Ystent should be selected, in which the outer diameter of the bron- 


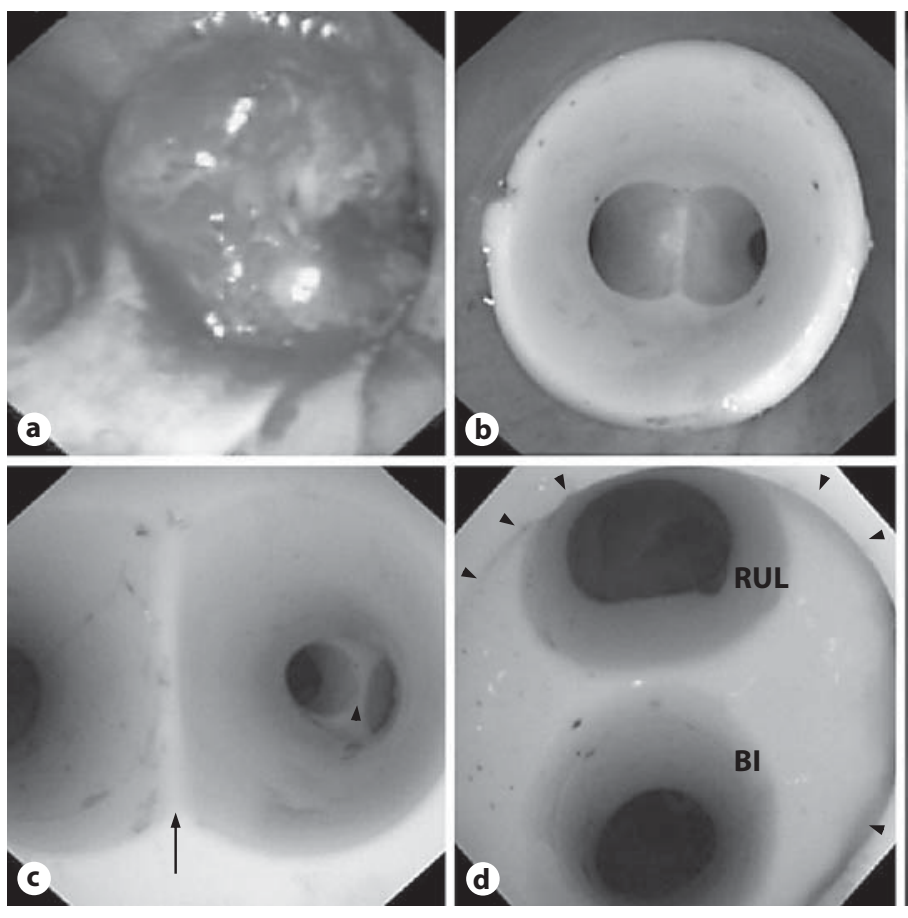

Fig. 2. a Squamous cell carcinoma involving the right main stem bronchus. $\mathbf{b}$ Proximal end of the additional second Y-stent on the main carina. c Bifurcations of the Y-stents covering the main carina (arrow) and the carina between the right upper lobe bronchus and the bronchus intermedius (arrowhead). d Y-stent covering the

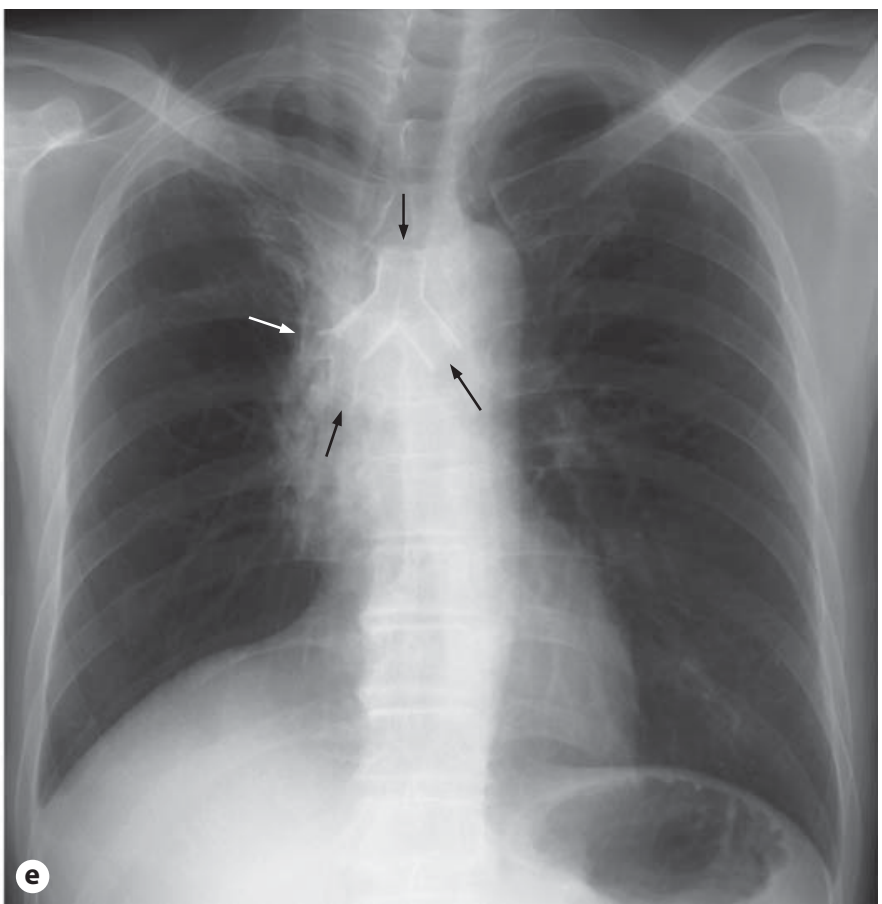

carina between the right upper lobe (RUL) bronchus and the bronchus intermedius (BI). The right bronchial limb (arrowheads) of the second Y-stent was inserted into the proximal limb of the first Y-stent. e Chest roentgenogram after placement of 2 Y-stents (arrows). chial limbs is equal to or slightly larger than the inner diameter of the proximal limb of the first Y-stent on RC 1. It is then cut to the appropriate length. Before the Y-stent is loaded into the stent introducer tube, its right bronchial limb is folded, sewn and tied with a nylon thread to maintain its folded shape (fig. 1a). The end of the nylon thread protrudes to the outside through the stent introducer tube for easy removal (fig. 1b). The Y-stent loaded into the stent introducer tube is pushed with a plunger into the trachea just above the main carina. The stent is then grasped with a rigid forceps and pushed so as to straddle the main carina. The folded right bronchial limb should be inserted into the proximal limb of the first Y-stent. The loop of the nylon thread is then cut with endoscopic flexible scissors (FS-1K, Olympus, Tokyo, Japan) (fig. 1c) under bronchoscopic control. Finally, the nylon thread is withdrawn, so that the right bronchial limb of the second Y-stent expands and fits into the proximal limb of the first Y-stent (fig. 1d).

\section{Case Reports}

Case 1

A 61-year-old man with lung cancer (squamous cell carcinoma) who had undergone chemotherapy and radiation therapy presented with progressive shortness of breath and coughing. Computed tomography revealed mediastinal adenopathy surrounding the right main stem bronchus and bronchus interme- dius which caused a narrowing of the airway. Therapeutic bronchoscopy under general anesthesia was performed using a rigid and flexible bronchoscope, which showed a tumor narrowing the right main stem bronchus (fig. 2a). Tumor resection and airway dilatation were performed with argon plasma coagulation, electrocautery, rigid bronchoscopic coring and balloon dilatation. Because RC 1 and the main carina had both been invaded, a Dumon Y-stent (outer diameter $14 \times 10 \times 10 \mathrm{~mm}$, radiopaque type; Novatech, Grasse, France) placement on RC 1 was performed followed by an additional Dumon Y-stent (outer diameter $16 \times 13$ $\times 13 \mathrm{~mm}$, radiopaque type) placement on the main carina (fig. 2b-e). Respiratory symptoms improved immediately, and the patient was discharged 1 week after the procedure. Although there were no stent-related adverse effects, the patient died from the progression of his lung cancer 166 days later.

Case 2

A 51-year-old man suffering from tracheobronchial stenosis due to esophageal cancer was referred for bronchoscopic treatment. He complained of severe dyspnea and presented with subcutaneous emphysema around his chest and neck. A chest roentgenogram demonstrated an enlarged mediastinum, reduced volume of the right lower lobe, subcutaneous emphysema and pneumomediastinum. Computed tomography revealed that his esophageal cancer had compressed the trachea, right and left main stem bronchus and the bronchus intermedius (fig. 3a). 

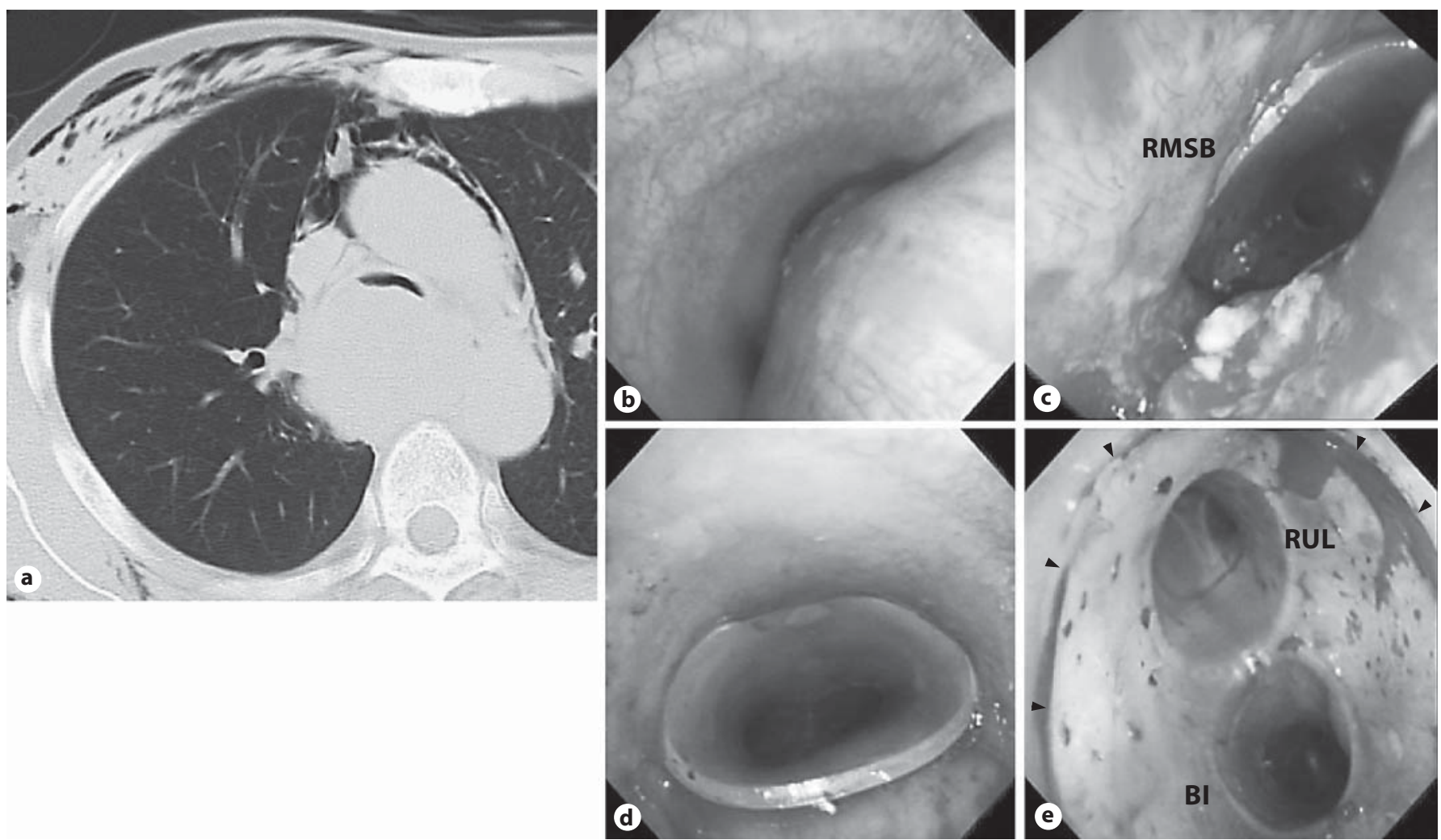

Fig. 3. a Computed tomography showing extrinsic compression of the trachea due to esophageal cancer, subcutaneous emphysema and pneumomediastinum. b Esophageal cancer compressing and involving the trachea. c First Y-stent placement in the right main stem bronchus (RMSB), arranged so as to straddle the carina between the right upper lobe bronchus and the bronchus in- termedius. d Proximal end of the additional second Y-stent on the main carina after the placement of stents. e Y-stent straddling the carina between the right upper lobe bronchus (RUL) and the bronchus intermedius (BI). The right bronchial limb (arrowheads) of the second Y-stent was inserted into the proximal limb of the first Y-stent.
Therapeutic bronchoscopy was performed using both a rigid and flexible bronchoscope under general anesthesia. Because an airway stenosis with extrinsic compression and intraluminal tumor invasion around both the main carina and RC 1 was observed (fig. 3b), a Dumon Y-stent (outer diameter $14 \times 10 \times 10 \mathrm{~mm}$, clear type) was placed on RC 1 (fig. $3 \mathrm{c}$ ) followed by an additional Dumon Y-stent (outer diameter $16 \times 13 \times 13 \mathrm{~mm}$, clear type) on the main carina (fig. $3 \mathrm{~d}, \mathrm{e}$ ). Respiratory symptoms and pulmonary function (forced vital capacity 1.95-3.72 liters, forced expiratory volume in $1 \mathrm{~s}$ 1.37-2.80 liters, peak expiratory flow 3.10$6.41 \mathrm{l} / \mathrm{s}$ ) improved immediately after the procedure, and the patient could return to the referring physician. He was still alive 4 months later with no stent-related adverse effects.

\section{Discussion}

Until the Y-stent was developed, the silicone straight stent with a side hole facing the opposite main bronchus [8] or plural straight stents [9] had been used for patients with stenosis around the main carina. However, such methods were not ideal, since they involved drawbacks such as occlusion of the side hole by intrusive tissue (tumor or granuloma), migration of the stents and tissue ingrowth from the junction of plural stents $[8,9]$. The Ystent, which is shaped to prevent migration or tissue ingrowth, has proved useful for airway stenosis around the main carina and should be the most suitable stent. However, in our clinical practice, we often encounter patients with airway stenosis around the main carina who should undergo not only the Y-stent placement but also an additional stent placement. In the largest study of 86 cases with silicone Y-stent placement, 21 reportedly required an additional straight stent placement for improved palliation [4]. The Y-stent can also be used for airway stenosis around RC 1 [6]. This method is particularly effective for maintaining the airway patency of the right upper lobe bronchus. The right upper lobe bronchi of our 2 cas- 
es were invaded by a tumor or closed off by extrinsic compression. Therefore, we selected the Y-stent and placed it on RC 1. Self-expandable metallic stent insertion into the right upper lobe bronchus might be feasible because of its easier insertion even into the regions inaccessible to a rigid bronchoscope, better adaptation to the transformed airway, thinner walls, and abundant type or size lineup in comparison with silicone stents $[10,11]$. However, even if it is feasible, for the carinal stenosis, plural metallic stents are required that has some disadvantages such as tissue ingrowth from the junction of stents or high costs.

The main carinal angle is different from the angle of RC 1 , so the angle of the limb of the Y-stent might not fit the RC 1 in some patients. In such patients, we should devise a technique such as follows. First, the orifice of the Y-stent should be cut at an angle to assure good flow and not toward the bronchial wall. Second, the right limb of the Dumon Y-stent is oriented a little more vertically than the left one, so insertion of the right limb into the bronchus intermedius may well overcome the problem. Additionally, commercially available Y-stents are designed for placing in the trachea, so they may be too large to place in the right main stem bronchus. A greater range in the sizes of commercially available Y-stents would be needed for ensuring the stenting on RC 1. Furthermore, we are hopeful that dedicated bifurcated stents with exclusive limb angles or sizes will be developed for more ideal stenting.
In our technique, the right bronchial limb of the Ystent for the main carina is inserted into the proximal limb of the Y-stent for RC 1, both functioning as a unit. If these stents were deployed separately rather than overlapped, a gap might have occurred between the axes of the proximal limb of the first stent and the distal limb of the second stent, so as to prevent smooth flow of air or secretions. Furthermore, tissue ingrowth from the region between the edges of the Y-stents is likely to occur. Thus, our technique provided optimal palliation for these cases. The accumulation of secretions inside the stent is one of the well-known stent-related complications [1]. In our cases, no special airway management, such as bronchoscopy to clear secretions or stent replacement, was required except for an occasional acetylcysteine or saline nebulization following the procedure. However, the thickness of the distal end wall of the second Y-stent or the length of the inserted stent might conceivably lead to mucus retention. Although no such complication was observed in our cases, careful stent maintenance (e.g. nebulization) to prevent mucus retention is needed as well as the usual silicone stenting.

In conclusion, bronchoscopic double Y-stent placement on both the involved main carina and RC 1 proved to be technically feasible, safe and effective in these 2 cases.

\section{References}

1 Dumon JF, Cavaliere S, Diaz-Jimenez JP, Vergnon JM, Venuta F, Dumon MC, Kovitz KL: Seven-year experience with the Dumon prosthesis. J Bronchol 1996;3:6-10.

-2 Bolliger CT, Sutedja TG, Strausz J, Freitag L: Therapeutic bronchoscopy with immediate effect: laser, electrocautery, argon plasma coagulation and stents. Eur Respir J 2006;27: 1258-1271.

-3 Dumon JF, Dumon MC: Dumon-Novatech Y-stents: a four-year experience with 50 tracheobronchial tumors involving the carina. J Bronchol 2000;7:26-32

4 Dutau H, Toutblanc B, Lamb C, Seijo L: Use of the Dumon Y-stent in the management of malignant disease involving the carina: a retrospective review of 86 patients. Chest 2004;126:951-958.
Prakash UBS, Fontana RS: Functional classification of bronchial carinae. Chest 1984; $86: 770-772$.

6 Oki M, Saka H, Kitagawa C, Kogure Y: Silicone Y-stent placement on the carina between bronchus to the right upper lobe and bronchus intermedius. Ann Thorac Surg 2009;87:971-974.

7 Amjadi K, Voduc N, Cruysberghs Y, Lemmens R, Fergusson DA, Doucette S, Noppen M: Impact of interventional bronchoscopy on quality of life in malignant airway obstruction. Respiration 2008;76:421-428.

8 Dumon JF: A dedicated tracheobronchial stent. Chest 1990;97:328-332.
9 Cavaliere S, Venuta F, Foccoli P, Toninelli C, La Face B: Endoscopic treatment of malignant airway obstructions in 2,008 patients. Chest 1996;110:1536-1542.

10 Miyazawa T, Yamakido M, Ikeda S, Furukawa K, Takiguchi Y, Tada H, Shirakusa T: Implantation of ultraflex nitinol stents in malignant tracheobronchial stenoses. Chest 2000;118:959-965.

11 Breitenbücher A, Chhajed PN, Brutsche MH, Mordasini C, Schilter D, Tamm M: Longterm follow-up and survival after Ultraflex stent insertion in the management of complex malignant airway stenoses. Respiration 2008;75:443-449. 